\title{
You Selfie, Therefore We Are: Indonesian Contemporary Art Consumption, Production and It's Dynamics
}

\author{
Salima Hakim \\ Universitas Multimedia Nusantara - Tangerang \\ salima.hakim27@gmail.com
}

\begin{abstract}
There has been a significant growth of enthusiasm and audience in the contemporary art events in Indonesia for the past ten years. Technology today plays a big role in creating complex yet dynamic relations between the audience, the artwork and the artist. It is widely recognized that nowadays, selfies are a common ritual also seen in art exhibitions and is often at the core of how the audience consumes and interacts with the artwork and the artist. This research will seek to examine how selfie as method of art consumption changes the function, relation as well as dynamics between the audience and the artwork as a mean of identity construction. Furthermore, this article will also try to investigate how selfie, as method of contemporary art consumption, to a certain extend influence or even determine the production aspect of the artwork done by contemporary artists, particularly in the Jakarta Art Scene.
\end{abstract}

Keywords: contemporary art, consumption, selfie, production, identity

\section{INTRODUCTION}

The Indonesian art scene, even though not limited to is in a broad sense often referred to the variety of movements and activities happening in three regions, which are Jakarta, Bandung and Yogyakarta. The concentrated activities are often considered as a logical consequence due to the fact that these three regions were amongst the first in which art education institutions were established. Each region stands with it's own unique backgrounds, characteristic of ideology and style which contributes to the overall identity of Indonesian art scene. Indonesian artworks done by modern and contemporary artists have been intersecting with the global contemporary art practice since around late seventies to the beginning of early eighties. Entering the early nineties however, these intersections became prominently intensified. Turner (2005) as referred to by Supriyanto (2013), acknowledge that Indonesian artworks started to be increasingly present in a range of 
international art events since around the nineties (p. 11). Market activities became even more intensified with the emergence of several art fairs, such as Hong Kong Art Fair in 2008, followed by Singapore Art Stage in 2011 to name a few (p.14). The growth of global art market activities also influenced the emergence of a different wave of art commercialization in Indonesia.

Hujatnika (2015) addresses that the 2000's marked the beginning of an art boom that were indicated by the proliferation of commercial and university galleries, private museums and many art initiative spaces in Indonesia (p. 194). Kusmara (2011) as cited by Hujatnika (2015) identify that there are around 37 galleries that emerged, expanded and survived in the course of early 2000's until around 2010 concentrated in several big cities in Indonesia (p.194). There was also a significant amount of growth of alternative art spaces commonly initiated by artist or communities, also known as artist-initiative space, which happened at the beginning of the 2000's period. These artist-initiative spaces often play an important role in helping to expand Indonesian contemporary art form and discourse. Hujatnika (2015) mentioned a few examples of the artist-initiative spaces that exists from around the 2000's era, such as Ruang Rupa, founded in Jakarta around 2001, Rumah Proses in Bandung in 2000, Commonroom Network Foundation established in 2002 along with Mes56 founded in Yogyakarta in 2002 (p.195). The thriving art scene of Indonesia is further heightened with high scale art events conducted in several regions in 2005. Hujatnika (2015) wrote that the growth of Indonesian art world also intensified in2005, with a national and international scale exhibition known as Biennale held simultaneously in four regions such as Jogjakarta, Jakarta, Surabaya and Bali (p.2).

The growth of activities, audience as well as attention to Indonesian contemporary art form and discourse, happening since the mid 2000's era, have sustained its importance and are indicating an even greater enthusiasm for the past five years. To give a glimpse of illustration in regarding to the contemporary art audience growth, data collected from The National Gallery of Indonesia's registration book, indicates a significant enlarging number of visitors coming to attend art exhibition held by or at The National Gallery of Indonesia. Mahendra (2017) stated that in 2013, the recorded number of people attending the National Gallery of Indonesia in Jakarta are as many as 65,804. The number increased in the following year and reached 77,842 visitors in 2014 . Further in 2015, there was another $84 \%$ leap in the number of people coming to exhibitions at the National Gallery of Indonesia, from 139,470 to approximately 257.309 visitors in 2016 (p. 2).

Indications of a rise in Indonesian contemporary art audience and activities are one way or another interconnected and highly influenced with the marketing strategy and positioning of several local as well as global brands. The need of product marketing can be seen as one of the determining factor that help spiked the interest towards Jakarta's contemporary art 
scene in particular, into a greater extend. Product advertisement through sponsorship of events by local or global brand is of course nothing new and has been around for decades. The tobacco industry's marketing strategy through advertisement and sponsorships of events for example, has been penetrating the landscape of Indonesia's urban cities and rural areas since as early as the beginning of the twentieth-century and have not changed much since. Even though not limited to, Nichter, Padmawati, Danardono, Ng \& Prabandari (2008) stated that tobacco advertising in Indonesia is among the most dominant, aggressive and innovative in the world. The tobacco advertisements saturate almost the whole entirety of the environment (p.98). Furthermore, Nichter et al., (2008) explained that Indonesian tobacco companies are politically and financially powerful, serving as one of the largest sources of government revenue. As a result, there is a relatively small portion of restriction imposed on cigarette marketing and advertising that molds Indonesia as a sort of 'advertising wonderland' (p.98).

Data collected from interviews implicate that in the period of 2010 to 2011, several notable cigarette brands started to focus intensively on the use of contemporary art scene in Jakarta, as a marketing strategy and product distribution medium. Leading tobacco companies mentioned by Hanusz (2003), such as PT. HM Sampoerna Tbk, PT. Gudang Garam Tbk and Djarum (p.120, p.136), began to rapidly appear as 'patrons' of the art, music and other cultural events, often combining them together and incorporating these activities as an integral part of their marketing strategy. A Mild, one of the most prominent product from the leading HM Sampoerna tobacco company for example, has been positioning music and contemporary art activities at the center of their brand promotion campaign. Nichter et al., (2008) stated in their research that A Mild's demographic target in 2008, was geared towards adults in the age range of twenty six to thirty five years old (p. 102). Starting in 2009 however, A Mild launched the Go Ahead advertisement campaign series that appear to include a younger crowd of audience, starting from eighteen up to thirty-five years old as their demographic target.

A Mild also embraced several artist initiative spaces in Jakarta and worked alongside public icons, well-known musicians, contemporary artists, renowned photographers, fashion stylist and other public influencer closely associated with the contemporary art scene. These figures functions as important aspect in constructing this new social and cultural activity. The role of art 'patrons' played by this tobacco giant, resulted in nation wide scale events such as Soundrenaline, Soundsations, Go Ahead challenge and many more. The Go Ahead challenge for example, provides creative workshops with photographers, visual artist and other public influencer, functioning as a knowledge sharing and distribution space. This promotional campaign also invites young people to submit their artworks for various types of challenges such as the 2017 Soundrenaline music poster competition, mural challenge, 
do your own totebag challenge, fabric dyeing challenge and many more (fig $1 \& 2$ ). These events offers youths the possibility of a close creative encounter with public influencers and participate as collaborators in contemporary art scene happening in Jakarta as well as other regions. Hence, the emergence of a young, stylish, bold and highly artistic identity of this constructed community is therefore inevitable, presenting an optional archetype crucial in the forming of identity. Weeks (1994) as referred to by Woodward (1997) stated that the non-essentialist position have stressed that identities are fluid, having different elements which can be reconstructed in new cultural conditions, and that they are not fixed essences locked into differences which are permanent for all time (p.26). These types of personality therefore function as a selection to choose from in the process forming of the fluid identity, mention earlier by Weeks.

Go/AheadPeople.id ]

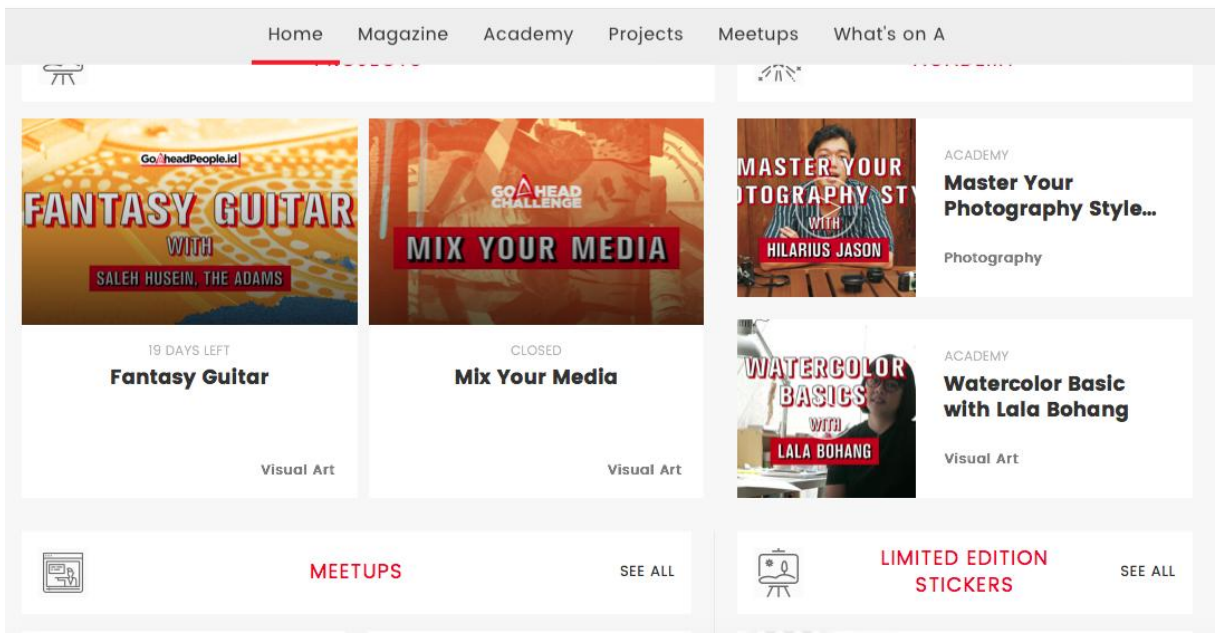

Figure 1. Screen shot of challenges from 2017 official A Mild Website (https://www.goaheadpeople.id)
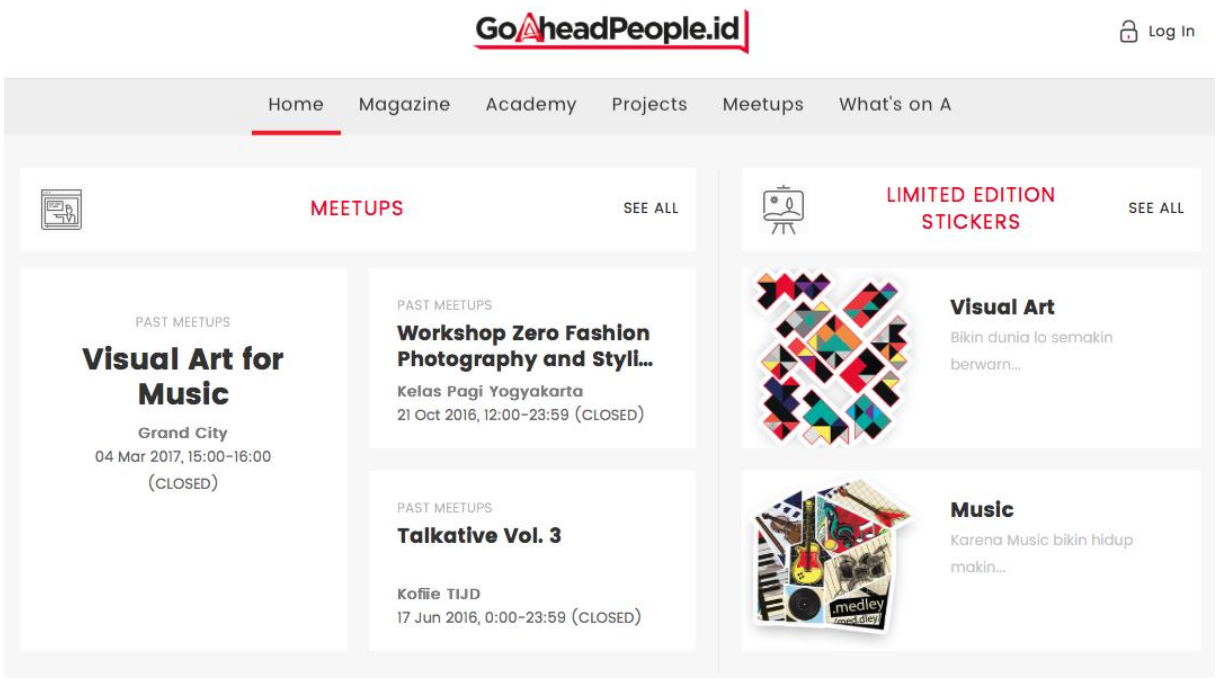

Fig.2. Screen shot of creative workshops from 2017 official A Mild Website. (https://www.goaheadpeople.id) 
The use of Indonesian contemporary art scene and activities as a marketing tool, to a certain degree impacts how people perceive, define, consume and even produce contemporary art today. Art events, exhibitions, activities as well as artworks through this marketing intervention, are represented in a different light than perhaps the previous era. It is no longer a highly sacred, secluded or exclusively belonging to a particular group of people, but represented in a more accessible, less restricted and available to a wider range of audience and interpretations. Hujatnika (2015) explained how the term 'globalization' is considered relevant to describe the fast moving transformation and acceleration of social change, due to the cause of migration, trade, foreign investment, and the international spread of systems of ideology, knowledge and technology (p.224). He then wrote that globalization became a popular keyword in explaining the condition of civilization in the dawn of the $20^{\text {th }}$ century, when all aspects of modern human lives are extremely integrated by language system, mass media and similar urban lifestyle (p.224). The rapid progressions of technological advancement greatly affected many aspects of human lives, which include how society gathers, produce, consume as well as distribute information or cultural products.

The year 2010 saw the birth of a technological advancement that has a profound impact on human lives and on how artworks are consume, which specifically cater to the need of selfdocumentation. Apple Inc. Company launches the Iphone four, a mobile phone device equipped with two cameras, one front and one rear camera that come with an LED (lightemitting diode) flash. The on-screen display of the device has doubled the number of pixels so that the image and video results have a higher resolution and clarity than previous products. These types of cameras are embedded in almost every smartphone and tablet used today. This new image making device, allow users to take self-portraits while looking at the screen and at the same time configure the desired composition, frame, angle and perfect focus. Henceforth, people and culture all over the world are making digital self-portraits known popularly now as selfies.

Tifentale (2015) wrote that selfie could be interpreted as an emerging sub-genre of selfportraiture within the broader field of amateur photography (p.8). Human's need of documenting the self through medium of art or photography goes way back to the nineteenth and early twentieth-century. Rawlings (2013) as cited by Tifentale asserts that from photography's earliest days, there has been a natural tendency for photographers to turn the camera towards themselves. Photography then, can easily be used as a tool for constructing and performing the self (p.9). This technological advancement of mobile phone as digital image making device subsequently leads the to explosion of selfies, describe in the oxford dictionary as self-portrait of a person who is taken by oneself, generally using a smartphone or webcam, to be uploaded to social media sites. Tifentale (2015) stated that 
in the 2010 period, the digital image making and image sharing complex, which she propose to call the 'networked camera' began to support and stimulate the production, distribution and consumption of digital amateur photography (p.3). Selfies are not taken simply for personal contemplative consumption but rather for the purpose of sharing the photograph through internet-based photo and video sharing application, one of which is known as Instagram, first published in 2010.

Social media exists in the virtual realm of the World Wide Web, which alongside technology profoundly impacts how human interact today. Marshall McLuhan predicted and mentioned this world fifty years ago with the term the global village. McLuhan (1967) wrote that ours is a brand-new world of all-at-once-ness. 'time' has ceased, 'space' has vanished. We now live in a 'global village'... a simultaneous happening. Information pours upon us, instantaneously and continuously. As soon as information is acquired, it is very rapidly replaced by still newer information (p.63). Indonesia like the rest of the world is currently also a resident of the global village, listed at number six as one of the biggest Internet users countries after China, The United States, India, Brazil and Japan (Hidayat, 2014). According to a study published in January 2017 by We Are Social, focusing on the development of worldwide Internet use, there is a significant growth of users in South East Asian regions, including Indonesia. In early 2017, there was a fifty one percent increase of Internet users from 88.1 million to 132.7 million users in the following year. Users of social media services in Indonesia have also increased in the past year, from 79 million to 106 million active users in 2017 (Pratama, 2017).

Tifentale in reference to Rawlings (2013) notes that the existence of this image making devices and online platforms of image circulation that allow users to instantaneously distribute the photograph, is what separates selfies from its analog predecessors. McLuhan, Fiore \& Agel (1968) explains that the unavoidable growth and use of technology are affecting cultures around the world. The cultures are in a way expanding as well as decreasing at the same time. As the ability to share, communicate and connect with other human being constantly progress, it has evolve into an inseparable part that humans cannot live without. The act of taking selfies, of documenting, recording and sharing daily activity through the assistance of technology and social media platform has became the norm and habit in expressing human existence today. Selfie can be seen as a sort of self-branding, an expressive act of individual storytelling in the purpose of confirming identity and at the same time expressing the need of belonging to a particular group of people. Van House (2011) observed that making, showing, viewing and talking about images are not just about how we represent ourselves, but contribute to the ways that we enact ourselves, individually and collectively and reproduce social formations and norms (p.31). This new way of existing directly impacts almost every aspect of human behavioral pattern, including how 
society today interact with contemporary artworks and scenes. Selfie as a form of existential validity effect many levels of how contemporary artworks and exhibition is consume and appear to acquire the capacity of changing both spatial as well as functional relation between an artwork, the audience and the artist.

Works of art has been understood as result of a collaborative process that involves many elements and division of labor. After an artwork is complete, it ought to be distributed for public consumption to produce the means needed to make further works or projects. Sedgwick (1999) stated that an art work is an art work because it has been 'baptised' as such through it's recognition in the art world of critics, connoisseurs, gallery proprietors, artists and audiences (Pg.15). Art needs to have a form of interaction with several chains of people. Not only does it need layers of collaboration with other artisans in the production stage, once it is done any works of art needs to be viewed, analyzed and interpreted in order to bring it to life. Becker (1982) as cited by Mackay (1997) explain that works of art, therefore are not the product of individual makers, they are rather, joint products of all the people who corporate via an art world's characteristic conventions to bring works into existence (p.152). This moment of recognition can be classified into a component known as consumption in Du Gay and Hall's (1997) diagrammatical theory, the circuit of culture (fig.3).

Depending on the theoretical framework used, there are several definitions in regarding to the meaning of consumption. Mackay (1997) points out that the current everyday use of the term are in reference to the economists' notion that consumption is about 'use' (p.2). Du Gay, Hall, Janes, Mackay \& Negus (1997) further explained that consumption usually refers to the purchase of a product in relation to its exchange-value or 'price' and 'usevalue'. In this sense consumption is therefore associated with the satisfaction of needs and wants (p. 86). Du Gay et al., (1997) also points out that from a contemporary sociological perspective, consumption is describe as the production of meaning through usage of any material culture (p.86). For example a group of young people who constantly use all black colored clothing, complete with black mascara and long black hair conveys a different sign, therefore meaning from those who wears soft pastel color clothing as their preferred fashion. Using all black colored material of clothing is a system of representation, which allows people to construct, convey and exchange meaning about them. The type of objects or artifacts and how it is purposely used is highly influential to the meaning constructed. Mackay (1997) acknowledge the importance of consumption as a crucial moment in the cultural circuit (p.1). 


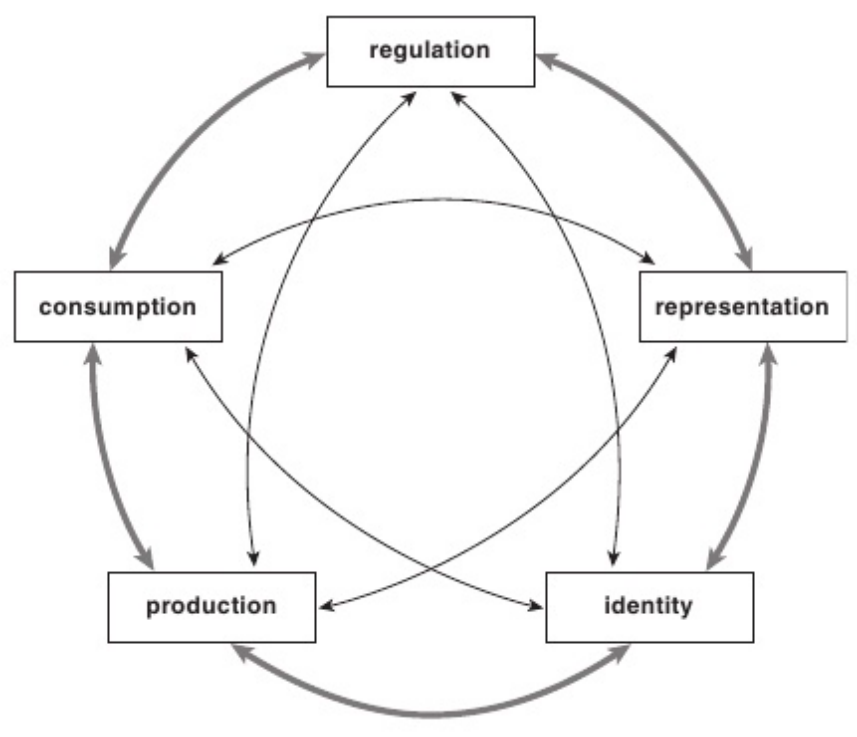

Fig.3. Paul Du Gay \& Stuart Hall's Circuit of Culture (image.slidesharecdn.com)

Each particular moment of the circuit need to be analyzed in order to have a complete identification and understanding of the process through which meanings of a cultural product or texts are made and shared within and between cultures. Mackay (1997) stated that the various moments are interrelated in the process of influence and feedback, where each components or stages are inextricably linked (p.1). The mode of consumption of Indonesian contemporary art scene have experience significant changes, highly influenced by the technological advancements of image making device, the social network platforms and by the trend of taking selfies, happening since the mid 2000's.

Previously, contemporary art works, exhibitions and other art activities in Indonesia have the tendency to exclusively belonging to a particular type of audience. Contemporary art scene and other relating activities prior to the mid 2000's, were commonly held in galleries or museums equipped with printed promotion materials such as catalogues and posters. Consumers are primarily groups of individual with direct involvement in the art world and presumably possess prior knowledge of the arts, artist and artworks through their educational system or level. These consumers are usually art collectors, dealers, art critiques, art enthusiast or art major students. Bourdieu (1984) stated that cultural needs are the product of upbringing and education. All cultural practices for example museum visits, going to a concert and preferences in literature or paintings are closely linked to educational level and secondarily to social origin (p.1). As also explained by Bourdieu (1984) a work of art has meaning and interest only for someone who possesses the cultural competence, that is, the code, into which it is encoded. The conscious or unconscious implementation of explicit or implicit schemes of perception and appreciation which constitutes pictorial or musical culture is the hidden condition for recognizing the style characteristic of a period, a school or an author...A beholder who lacks the specific code feels lost in a chaos of sounds 
and rhythms, colors and lines, without rhyme or reason (p.2). Art scenes and other artistic activities thus are commonly understood as a product consumed and produced by a specific group of people with prior knowledge of the art world. These 'art educated' groups of people are often considered of a different kind from the majority, for possessing the knowledge familiar only to a certain social hierarchy.

A collective way of consuming an artwork prior to the mid 2000's is usually done by contemplating the formal qualities as well as the intrinsic value of the work. This is done in order to understand the craftsmanship, artistic style, meaning as well as the ideological standpoint of the artist resulting in the judgment of taste function as the marker of people with similar cultural capital, therefore, a certain class. Bourdieu (1984) explained that in the arts consumption domain, cultural capital consists of a generalized 'aesthetic disposition' or the capacity to conceive aesthetically objects and styles hailing from heterogeneous realms, whether classically affiliated with the fine art or not. The aesthetic disposition...can be defined as the capacity to consider in and for themselves, as form rather than function (p.3).

An individual knowledge and preference of a particular artist, genre or style of an artwork is a mean of showcasing one's cultural competence in deciphering meanings of the work of art. In the context of Indonesian modern and contemporary art consumption prior to the mid 2000's, the knowledge of the historical, social and ideological background appear to be the tools needed in order to gain understanding of the formal qualities as well as symbolic meaning of an artwork. This kind of skill is also acquired from an individual's education level accessible depending on the levels of their social class. Further on Bourdieu (1984) points out that the socially recognized hierarchy of the arts, the genre, schools or periods corresponds to a social hierarchy of the consumers. This predisposes taste function as marker of 'class' (p. 1-2). The types of artist, genre or art period acknowledge by an individual as their favorite also serves as a mark of which social class they belong to or is coming from. Using Bourdieu's terms, education provided certain social groups with access to what is called cultural capital (Bourdieu, 1986). The mode of art consumption, which require a cultural capital that consist of a particular type of knowledge and interpretation of an artwork happening in Indonesia prior to the mid 2000's era is perhaps what Peterson (1992) mention as univore, commonly associated with high brow culture.

Along with the role of global brands in shaping and manufacturing contemporary art scene and activities as the 'ideal' community, there appear to be an emerging wave of art consumers coming from various geographic and demographic backgrounds starting in the early 2010. Consumers of Indonesian contemporary artworks and activities are no longer restricted to groups or individuals coming from a specific social hierarchy but expanded into a wider range of age group and social class. An art exhibition no longer interacts only 
with groups of people equipped with prior art world knowledge, but also with people coming from various social hierarchy often detached of any knowledge of the art scene which appear to abolish the segmentation of a highbrow or lowbrow audiences. Further research will be needed to validate this basic assumption, but this new type of consumer is perhaps what Richard Peterson (1992) acknowledges as cultural omnivorousness.

This new type of consumer also profoundly impact changes that occur in the practice of Indonesian contemporary art scene consumption. If the collective way of consuming an art exhibition prior to the mid 2000's is done by contemplating the extrinsic as well as the intrinsic value of the art work assisted by any previous knowledge, selfie and the act of taking it, is on the top of the list and appear as one of the most prominent way of consumption in regarding to this alleged cultural omnivores. From observations conducted at several contemporary art activities held in Jakarta, a wider age group of consumers ranging from fourteen to twenty five years old from various cultural backgrounds, attend art events with the purpose of finding visually appealing and intriguing artworks to take selfies with. Consumer and art relation are therefore no longer limited to a contemplative moment in the pursuit of understanding an artwork from a certain philosophical, ideological or aesthetic point of view, but encompass a different kind of interaction in which artworks are being used as backgrounds catering to the need of taking selfies.

If Du Gay et al., (1997) from a contemporary sociological perspective describe consumption as the production of meaning through usage of any material culture (p.86), the act of taking selfies with an artwork can perhaps also be define as a mean in which symbolic meanings are produced. Taking a selfie at an art exhibition, in front of an artwork or in any art activities for the purposes of later publishing it in social media platforms, can produce meaning of belonging to a particular type of group or people. In this context a selfie at an art exhibition, serve as a sign that an individual belongs to or is a part of the contemporary art scene, which usually comes with its own set of meanings and representations. Mackay (1997) proposed consumption as not merely the act of buying goods, but the fundamental process or the very material by which people construct their identity (p.19). Baudrillard (1988) as cited by Du Gay further stated that material culture does not simply, nor primarily have the use or exchange value, but more importantly it has an 'identity' value (p.45). What we consume therefore might have the capacity to produce and circulate meaning for the purpose of ideological as well as social construction of self. Taking a selfie with an artwork at an art exhibition for example not only signifies our belonging to the contemporary art scene but also signifies our identity and social standing.

As previously mentioned, global brands have a significant role in representing contemporary art scene and activities as a desirable lifestyle option for young people to engage with, offering many creative and cultural goods as a part of their campaign. 
Bourdieu (1984) as cited by Mackay (1997) stated that consumption is the articulation of a sense of identity. Our identity is made up by our consumption of goods... So display -to ourselves and to others- is largely for symbolic significance, indicating our membership of a particular culture (p.4). Consumption of cultural goods provided by contemporary art events manufactured by the global brands indicates an individual's membership of the art scene, and signifies their identity as a part of a constructed 'desirable' community, commonly associated with high artistic interest and skill as a part of their identity. A selfie of the membership of the art scene, illustrated in (Fig. 4) establish symbolic significance that sanction the sense of belonging as well as classifies one's identity of being artistic. Van House (2011) observed that making, showing, viewing and talking about images are not just about how we represent ourselves, but contribute to the ways that we enact ourselves, individually and collectively and reproduce social formations and norms (p.31).

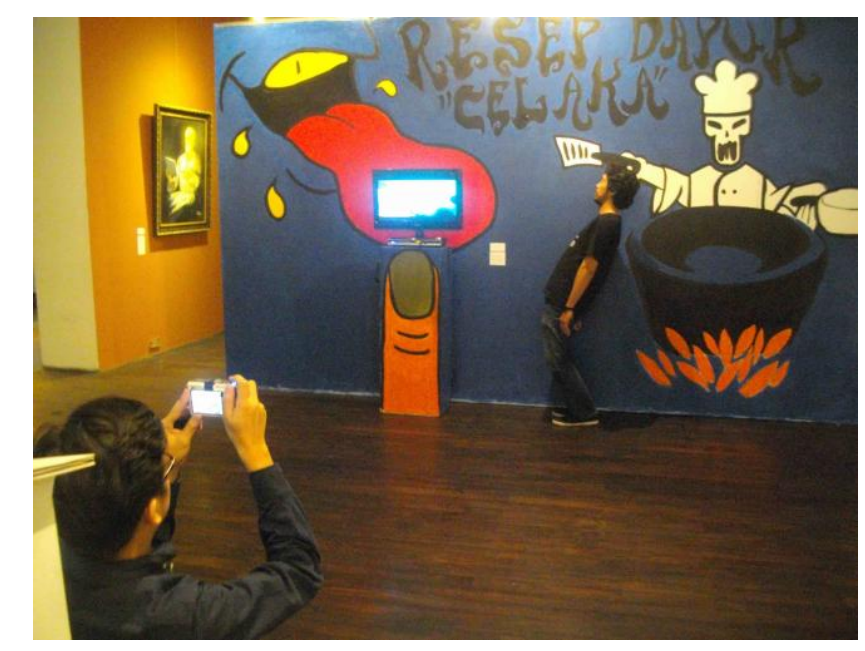

Fig. 4. A selfie taken in Rusuh Resah art exhibition held in Jakarta in 2014. (personal documentation)

Bordieu (1984) cited by Mackay (1997) also points out that culture is all about the processes of identification and differentiation. If identities are produced through practices of distinction, we distinguished ourselves by the taste distinction we make - for example, between 'cultivated' and vulgar' (p.4). Selfies as a mode of art consumption function as a sign of differentiation with other, who are not engaging in this particular activity, therefore is not a part of the entirety of Indonesian contemporary art scene. People differentiate themselves through engagement to the art world and would rather distinguish themselves as an 'artsy' individual with a taste for the art world rather than 'plain'. This refers to what Bourdieu (1984) stated that no judgement of taste is innocent. The different choices of artistic preference are in a sense all distinctions, meaning that all choices made in opposition to those made by other classes. We choose to take selfie in front of or with an 
artwork to identify ourselves with a certain type of identity or group and at the same time, distinct ourselves from those who do not share the same symbolic goods.

Mackay (1997) points out that using the approach in cultural studies, consumption is seen as an active process, often celebrated as pleasure and has its own practices, tempo, significance and determination (p.2). Subculture theorist that emerged largely from the Birmingham Centre for Contemporary Cultural Studies in the 1970s focused on the exploration of the pleasure of consumption as focus on many of their research (p.5). Serving as critique of the Frankfurt School that sees consumers as being passive and easily manipulated, Mackay (1997) further stated out that subcultural theorist propose a contrasting notion that young consumers were active, creative and critical in appropriation and transformation of material artifacts or goods which they consume (p.6). This active nature of consumption can be identified through several modes of how the selfie taken at art exhibitions or with an artwork is 'designed' for social media publication.

Design number one positioned the artwork either at the center of, as a part of or as background for taking selfies for public distribution through social media photo sharing platforms. This design then provides detail information of the artist's name, title of the artwork, year of production and caption of the artwork, on the published photo (Fig.5). Acknowledgement of the artist and the artwork documented in the selfie, signifies that the individual doing so is equipped with prior knowledge of the quality of the art works, and is perhaps a loyal observer or admirer of the artist, coming from a cultural or social background closely related or belonging to the contemporary art scene. Designing a selfie with an artwork complete with the knowledge and artistic appreciation of the artwork function as signs of the individual's cultural capital as a part of identification and differentiation of self. As Bourdieu (1984) cited by Mackay (1997) puts it, taste classifies the classifiers. Social subjects are classified by their classification, and distinguished themselves by the distinctions they make, and thus class difference is constructed through consumption. 


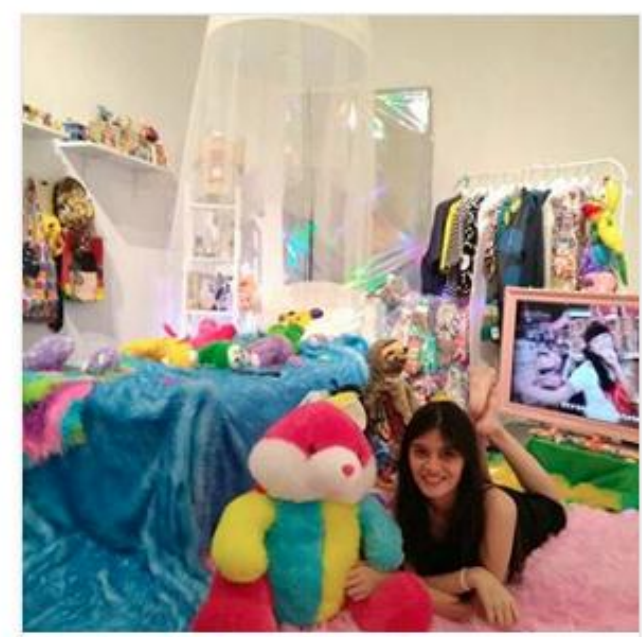

"If I like the dress, why can't I wear it?" . .Opposing gender binarism, Wangsit Firmantika amplifies awareness of gender issues by presenting pangender



Mengenal Wangsit yang dilihat pertama kali tentu saja keunikannya dalam berpakaian, lalu rambut. Jujur, melihat Wangsit awalnya bingung,

$8 \vee 235$ 2:03 AM Jun 4, 2017

Fig. 5. Design one of a selfie at Dialogue Exist 4 exhibition held in Jakarta in 2017. (https://www.pictaram.org/hashtag/dokidokibedroom)

Design number two positioned the artwork either at the center, a part of or as a background for taking selfies, without providing any detail information of the artwork, in the published photo. Artworks, art space or exhibitions serve as backgrounds and seem to be appropriated as an ornamental element that heightens and visually brightens the need of taking selfies (Fig 6). Instead of providing the published photo with information regarding the artwork, consumers of this kind substitute the caption of the artwork with quotes often appropriated from inspirational quotes sites or other well-known online image sharing platforms such as Tumblr, to name a few. Through this second selfie design, an artwork or an art exhibition appear to be transformed into a complimentary ingredient of an individual statement of self-expression. Designing a selfie that are visually pleasing that appropriates artworks and combine them with quotes, even though deprived of any art related acknowledgement also function as a sign that conveys a sense of a particular type of identity in which the individual is trying to construct. Participation in the contemporary art scene showcased in the selfie, acts as a signifier that an individual belongs to and is a part of the contemporary art scene regardless of how isolated their understanding of the artwork is. Baudrillard (1988) as cited by Mackay (1997) argues that we become what we buy; signs and signifying practices are what is consumed -even if we do not consume the product (p.5). In a sense, this is also a representation of the individual's cultural capital as a part of identification and differentiation of self. 


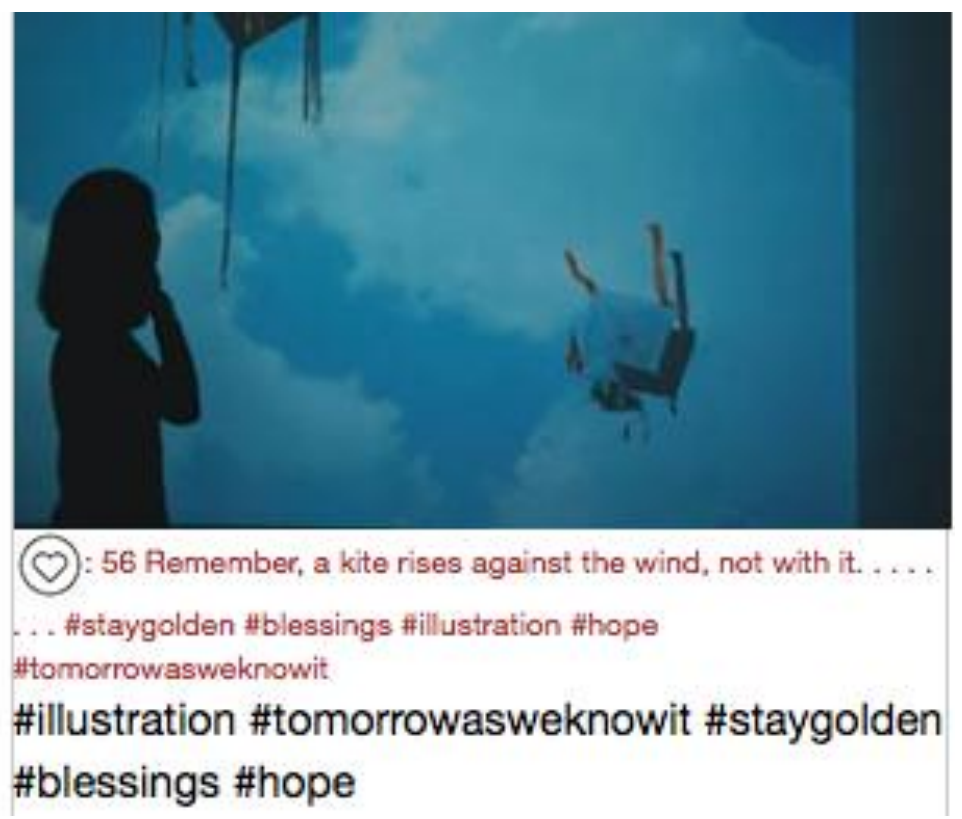

Fig. 6. Design two of a selfie at Dialogue Exist 4 exhibition held in Jakarta in 2017. (https://www.pictaram.org)

The visual qualities of both of these selfie design are more often than not enhanced and amplified through the use of various accessible photo filters and photo editing applications. The advancement in technology and applications allow people to elevate the photograph taken into a standard that we see fit. People are able to change colors, saturations, brightness and contrasts as well as changing the whole outlook of not only the individual taking the selfie, but also the artworks included in the frame.

Michel De Certau (1984) as reffered to by Mackay (1997) points out that the active nature of consumption can be seen through the use of a bricolage, in which consumers appropriated, re-accented, rearticulated or trans-coded the material of mass culture to their own ends, through a range of everyday creative and symbolic practices (p.6). The previous passage stated that consumers are actively transforming the function of a contemporary artwork using them as backgrounds or decorative elements in producing a selfie. Artworks in this sense seem to lose its contemplative function, but at the same time gain another. The appropriated images of the artworks in the selfie, are further re-accented through the use of digital imaging filters and color enhancement applications. Consumers also rearticulate the appropriated artwork image by combining them with personal statements or popular quotes also appropriated from other source. The use of bricolage indicates consumer's capability of rearticulating as well as transforming mass and cultural products according to their own needs of self-expression. Through such process of appropriation and transformation, identities are constructed (de Certau, 1984 in Mackay, 1997. p.6). 
Meaning are not only transmitted, passively received, but rather are negotiated by active audiences. De Certeau (1984) also points out that products may be imposed by capitalism, but the way of using them are not. Different groups will find the means of consuming each product differently and find use of it. The method of consumption that includes process of appropriation, manipulation and transformation of the artworks in adjustment to the needs of circulating meanings as a process of constructing identity, is in this context a signifier to the notion that consumption is not the end of a process, but the beginning of another, thus itself a form of production, or what Michel de Certeau (1984) cited by Mackay (1997) describes as 'secondary production' (p.7).

Several key arguments can serve as a temporary conclusion in regarding to the changing dynamics of Indonesian contemporary art consumption discussed in this first phase of this research paper. The first argument consists of the notion that questions the relation of people in regarding to the practice of consumption. Are we therefore the passive victim of consumption as portrayed by the Frankfurt Mass Culture School? or are we free liberated consumers possessing an active power in transforming and re-articulating cultural products to fit accordingly to our own needs in the everlasting cycle of production, distribution and consumption? Or are we as Mackay (1997) stated perhaps standing somewhere in between as creative, active individuals, working with a range of materials and through several modes of consumption practices trying to construct meaning and forming identities and the same time trying to make sense of our own everyday life? (p.10). Further elaborate and detail research is still being conducted in order to provide answers to all the key argument including to the notion of: if consumption demonstrates the active role of consumers in transforming the function as well as symbolic meaning of an artwork, to what extend does this secondary production influence or even determine the production aspect of an artwork, produce by artist in the Indonesian contemporary art scene?.

\section{REFERENCES}

Baudrillard, J. 1988. Jean Baudrillard: Selected Writings. Cambridge: Polity Press.

Bourdieu, P. 1984. Distinction. London: Routledge \& Kegan Paul.

De Certau, M. 1984. The Practice of Everyday Life. Berkeley, CA: University of California Press.

Du Gay, P. 1997. Production of Culture/Culture of Production. London: Sage.

Edgar, A., Sedgwick, P. 2002. Cultural Theory, The Key Concepts. London: Routledge. Hall, S. 1997. Representation: Cultural Representations and Signifying Practices. London:

Sage Publications Ltd.

Hujatnikajennong, A. 2015. Kurasi dan Kuasa: Kekuratoran dalam Medan Seni Rupa

Kontemporer di Indonesia. Tangerang: CV.Marjin Kiri.

Mackay, H. 1997. Consumption and Everyday Life. London: Sage Publications Ltd. 
Mahendra, J. 2017. Sudut Pandang Baru Terhadap Revitalisasi dan Adaptasi Kompleks Gedung Galeri Nasional Indonesia. Depok: Seminar Heritage IPLBI.

McLuhan, M., Fiore, Q, \& Agel, J. 1968. War and Peace in the Global Village. New York: Bantam Books.

Mc Luhan, M., Fiore, Q, \& Agel, J. 1967. The Medium is The Massage. New York: Bantam Books.

Nichter, M., Padmawati, S., Danardono, M., Ng, N., Prabandari, Y., Nichter, M. 2017. Reading Culture from Tobacco Advertisement in Indonesia. Group BMJ Journals.

Peterson, R.A., Kern, R.M. 1996. Changing Highbrow Taste: From Snob to Omnivore. American Sociological Association.

Supriyanto, E. 2013. Indonesian Contemporary Art: Becoming Contemporary, Becoming Global. Berlin: Distanz Verlag.

Tifentale, A. 2014. The Selfie: Making Sense of the Masturbation of Self-Image and the Virtual Mini-Me. The City University of New York.

Van House, N. A. 2011. Personal Photography, Digital Technologies and the Uses of the Visual. Journal Visual Studies 26, no. 2.

Woodward, K. 1997. Identity and Difference. London: Sage Publications.

Anwar, L.A. 2015. Retrieved from http://print.kompas.com/baca/dikbud/kebudayaan/2015/12/28/Anak-anak-MudaSerbu-Galeri-Nasional.

Fajrina, H.N. 2016. Retrieved from https://www.cnnindonesia.com/teknologi/20160623112758-185-140353/ada-22juta-pengguna-aktif-instagram-dari-indonesia/.

Hadi, R. 2016. Retrieved from http://jakartavenue.com/read/article/2016/12/30/17716/Kaleidoskop-Aktivitas-GNI2016-dan-Menyongsong-Aktivitas-2017-Galeri-Nasional-Indonesia

Hidayat, W. 2014. Retrieved from http://tekno.kompas.com/read/2014/11/24/07430087/Pengguna.Internet.Indonesia. Nomor.Enam.Dunia

Kemp, S. 2017. Retrieved from We are Social https://wearesocial.com/special-reports/digitalsoutheast-asia-2017

Pratama, A.H. 2017. Retrieved from https://id.techinasia.com/pertumbuhan-penggunainternet-di-indonesia-tahun-2016 